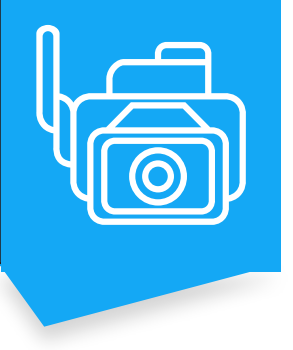

\title{
Una aventura con olor a café
}

Por: Daniel Orlando Ávila Narváez,

Mateo Jacob Hernández Melo,

Leonardo Alfredo Vargas Ortiz .

Estudiantes de Animación y

Posproducción Audiovisual

Dentro de la población joven de Colombia existe una falta de interés por las tradiciones del cultivo y procesamiento de este producto, llevando a esta población a optar por otras formas de trabajo y abandonando sus sitios de origen desplazándose a las grandes ciudades. El proyecto "Una aventura con Olor a Café" tiene como finalidad recolectar información concerniente a las etapas de producción del café colombiano, de ese modo despertar interés en la población por medio de un videojuego, el cual consiste en mostrar las fases de producción del café, incentivando al jugador a adquirir conocimiento acerca de la elaboración de este producto. 

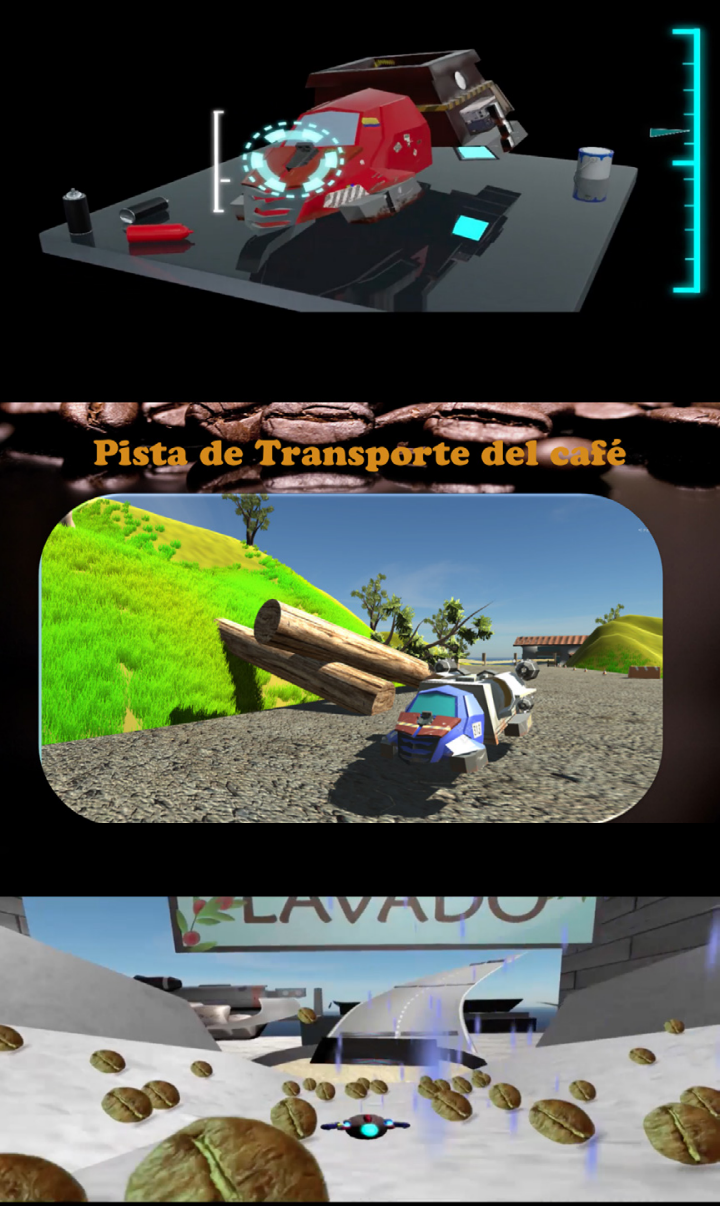

$40 \times-204 \times 3$
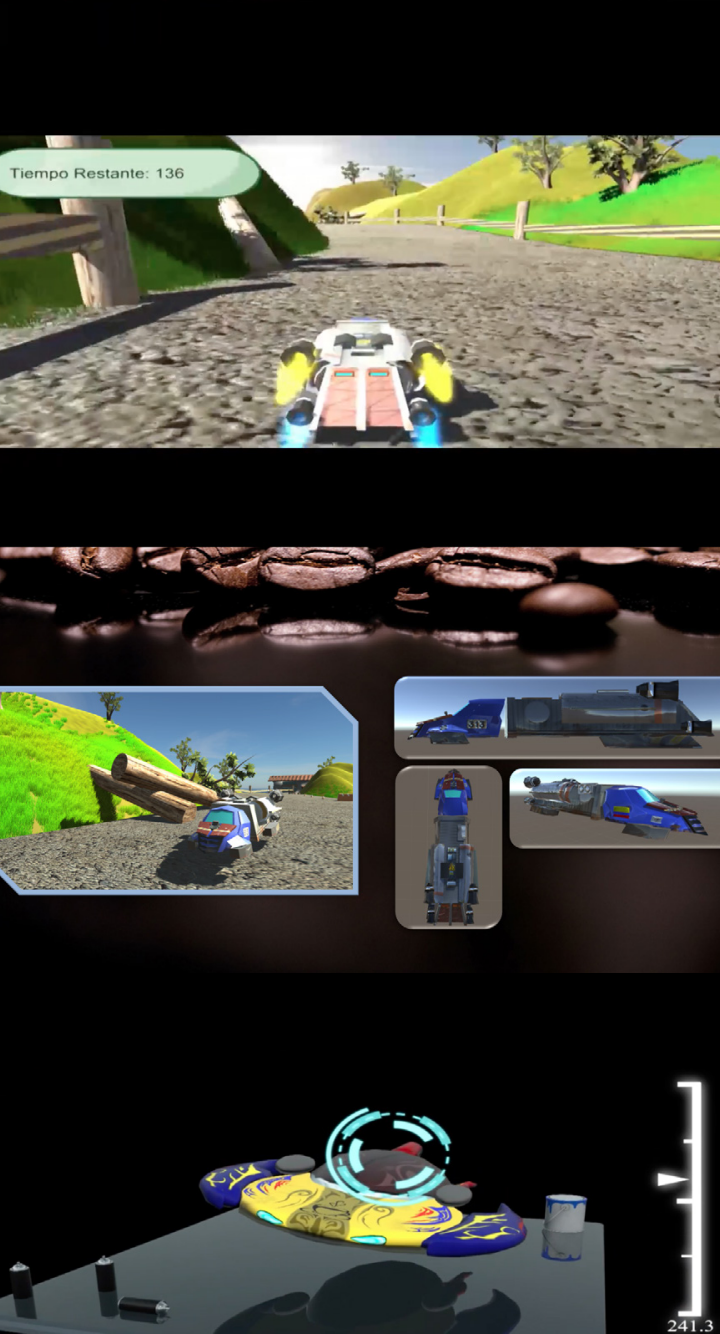

\section{Lista de Referencias}

Baqué Café. (s.f.). Baqué. Obtenido de http://www.baque.com/

Belli, s., \& López Raventós, C. (2008). Breve historia de los videojuegos. Athenea Digital. Revista de Pensamiento e Investigación Social 2008 (14), 160, 161

Café de Colmbia. (2010). cafédecolombia.com. Obtenido de El cultivo: http:// www.cafedecolombia.com/particulares/es/sobre_el_cafe/el_cafe/el_cultivo/

Carros Mitula. (s.f.). Mitula. Obtenido de https://carros.mitula.com.co/carros/ chevrolet-apache-gas

Colombia para todos. (7 de Enero de 2012). Con un exquisito café alcalde de Montenegro recibirá a turistas de otras partes de Colombia y el mundo. Colombia para todos.

Díaz Arango, F. O. (2016). ). Administrative and operational strategies of the coffee processing industry department of Caldas (Colombia). Revista Facultad Nacional de Agronomía, Medellín, 69(2), 7894, 7895.

El Espectador. (10 de Febrero de 2009). elespectador.com. Obtenido de Actualidad: http://www.elespectador.com/impreso/actualidad/articuloimpreso116795-magia-del-eje-cafetero

Etxeberria, X. (1998). Videojuegos y educación. Comunicar 1998 (10), 177. Obtenido de http://www.redalyc.org/articulo.oa?id=15801026

Federación de Cafeteros. (29 de Abril de 2016). Ya están gestionados importantes apoyos para la renovación de 68 mil hectáreas de café en 2016. Obtenido de Federacióndecafeteros.org: https://www.federaciondecafeteros.org/algranofnc-es/index.php/comments/ya_estan_gestionados_importantes_apoyos_para_ la_renovacion_de_68_mil_hectar

García, A. (2009). Ethnographic Approaches to the Internet and Computer-Mediated Communication. Journal of Contemporary Ethnography

Grijalbo, J. (1986). Grijalbo. Barcelona: Ediciones Grijalbo, S. A.

Guhl, A. (2009). Café, bosques y certificación agrícola en Aratoca, Santander. Revista de Estudios Sociales 2009 (32), 116, 117. 
Gutiérrez Flórez, J. M., \& Copete López, H. (2009). Hacia la mejora del secado mecánico del café en Colombia. Tecno Lógicas 2009 (23), 113, 114. Obtenido de http://www.redalyc.org/articulo.oa?id=344234316007

Hine, C. (2004). Etnografía Virtual. Colección. Nuevas Tecnologías y Sociedad. Editorial UOC

Ibáñes, J. (1991). El Regreso del sujeto: la investigación social de segundo orden. San Pedro del Romeral.

JUGO. (22 de 06 de 2013). gamificación. Obtenido de http://www.gamificacion. com/que-es-la-gamificacion

León, J. (2000). Café Arábigo. En J. León, Botánica de los cultivo tropicales (edición 2) (págs. 194, 199). San José: Agroamérica.

Mead, G. (1999). Espíritu, persona y sociedad: Desde el punto de vista del conductismo social.

Ortiz Soto, U. (29 de Junio de 2011). Eje Cafetero: "Patrimonio cultural de la Humanidad". Obtenido de elespectador.com: http://www.elespectador.com/ opinion/eje-cafetero-patrimonio-cultural-de-la-humanidad-columna-280917

Sampieri, R. H. (2010). Metodología de la investigación. Mc Graw Hill.

Sanz, J. R., \& Oliveros, C. E. (2011). Ingeniería y Café en Colombia. Revista de Ingeniería 2011 (33), 100, 112. Obtenido de http://www.redalyc.org/articulo. oa?id=121022658011

Tascón, O., \& Uribe, S. (2011). Ingeniería y Café en Colombia. Revista de Ingeniería 2011 (33).

Vizer, E. A. (2009). Dimensiones de la comunicación y de la información: la doble faz de la realidad social. Signo y Pensamiento 2009 XXVIII (55).
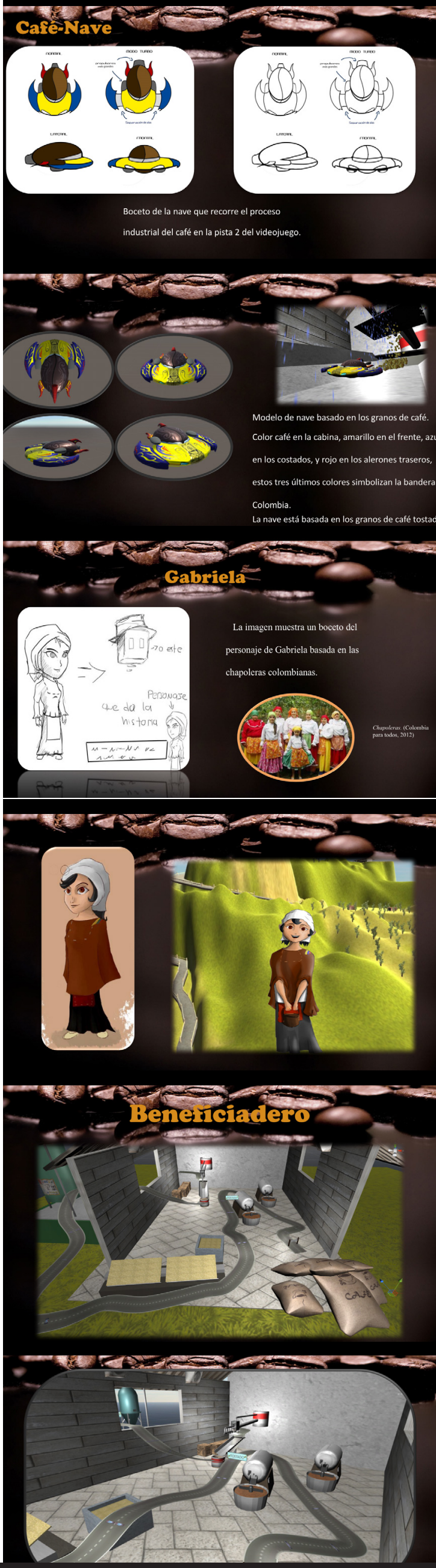